\title{
Effects of the CDK-inhibitor CYC202 on p38 MAPK, ERK1/2 and c-Myc activities in papillomavirus type 16 E6- and E7-transformed human keratinocytes
}

\author{
GANKA N. ATANASOVA ${ }^{1,3}$, ANTONIA R. ISAEVA ${ }^{1}$, NIKOLAI ZHELEV ${ }^{2}$, \\ YVES POUMAY ${ }^{3}$ and VANYO I. MITEV ${ }^{1}$ \\ ${ }^{1}$ Departments of Chemistry and Biochemistry, Medical University of Sofia, 1431 Sofia, Bulgaria; \\ ${ }^{2}$ School of Contemporary Sciences, University of Abertay, DD1 1HG Dundee, UK; \\ ${ }^{3}$ Cell and Tissue Laboratory, University of Namur (FUNDP), B-5000 Namur, Belgium
}

Received March 23, 2007; Accepted May 28, 2007

\begin{abstract}
In the present study, we have investigated the effect of the chemical CDK-inhibitor CYC202 on E6 and E7transformed keratinocytes, in which the function of the cellular cell cycle inhibitor $\mathrm{p} 21^{\mathrm{Cip} 1}$ is abrogated by the viral genes. The cyto-toxicity and the inhibition of the cell growth were analysed by MTT assay and analysis of DNA synthesis respectively. The effect on some signalling molecules was tested by Western blot analysis. CYC202 effectively inhibited the proliferation of E6 and E7 keratinocytes in a dosedependent manner. Treatment with CYC202 strongly increased the activity of p38 MAP kinase. Furthermore, it inhibited ERK1/2 at the highest concentration used and had no effect on the activity of JNK1/2. CYC202 also increased the phosphorylation of HSP27 and decreased the phosphorylation and DNA-binding activity of the transcriptional regulator $\mathrm{c}-\mathrm{Myc}$, in correlation with the corresponding upstream kinases p38 MAPK and ERK1/2. Our results provide additional data for the anti-proliferative actions and potency of the chemical CDK-inhibitor CYC202.
\end{abstract}

\section{Introduction}

CYC202 is the $R$-enantiomer of roscovitine, a specific inhibitor of the cyclin-dependent kinases, particularly of CDK2 and CDK7 (1). Most of the studies with CYC202 were directed to delineate its anti-tumour activities (2-4). Considerable attention was focused on investigating the anti-cancer properties of CYC202, however, this agent is also a potent

Correspondence to: Professor Vanyo I. Mitev, Departments of Chemistry and Biochemistry, Medical University of Sofia, Str. Zdrave No. 2, 1431 Sofia, Bulgaria

E-mail:mitev@medfac.acad.bg

Key words: keratinocytes, HPV16 E6 and E7 genes, CYC202, MAP kinases inhibitor of the cellular growth of normal fibroblasts (5) and normal epidermal keratinocytes (6). Since tumour cell types are very sensitive to this compound, CYC202 is undergoing clinical trials as a cancer treatment $(7,8)$.

Human papillomaviruses (HPV) are small DNA viruses that are frequently found in cervical carcinomas and in some oral and laryngeal cancers, especially the high-risk subtypes, including the most common types HPV16 and HPV18 (9). In order to amplificate its genome in host cells, HPVs have developed several strategies to ensure S-phase entry and to overcome eventual cell cycle arrest. Two of the early viral genes, E6 and E7 are involved in the maintenance of proliferation of the host cell. Together, these genes efficiently immortalize normal human keratinocytes in vitro (10). The HPV16 E6 and E7 gene products stimulate in the host cells the cell cycle transition $G_{1}-S$ in the presence of various $G_{1}$ arrest signals, through interaction with key components of cellular growth-regulatory pathways (11). E6 interacts with p53 and leads it to proteasome degradation. The main targets of E7 are the proteins from the retinoblastoma $(\mathrm{Rb})$ family (11). E7 interacts with the hypophosphorylated form of Rb and this interaction results in the release of E2F transcription factors. Due to the increased transcription, the amount of cyclin E is elevated (12). The expression of E7 prevents inhibition of cyclin E-CDK2 by the cellular inhibitor p21 $1^{\text {Cip } 1}$ and the progression of the cell cycle is ensured $(13,14)$.

In the present study, we investigated the effect of the chemical CDK-inhibitor CYC202 in HPV16 E6- and E7transformed keratinocytes, in which the function of the cellular CDK-inhibitor $\mathrm{p} 21^{\mathrm{Cip} 1}$ is abrogated. The cytotoxicity of CYC202 and its effect on cellular proliferation were analysed. We also analysed the effect of CYC202 on some signalling molecules, which are involved in the control of cell proliferation, differentiation, and survival. CYC202 effectively inhibited the proliferation of E6 and E7 keratinocytes in a dose-dependent manner. Treatment with CYC202 strongly increased the activity of p38 MAP kinase and the phosphorylation of its substrate HSP27. In contrast, the phosphorylation of ERK1/2 MAPK was inhibited by the highest concentration of $\mathrm{CYC} 202$, and this effect 


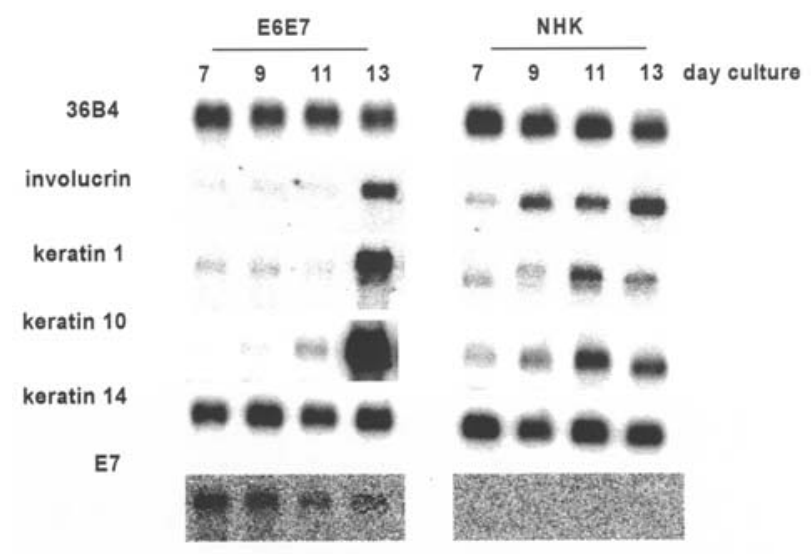

Figure 1. Northern blot analysis of the expression of epidermal differentiation markers in normal and in E6E7-transformed keratinocytes. Poly(A) RNA were extracted from normal keratinocytes (NHK) and transformed keratinocytes (E6E7). Northern blot analysis was performed with cDNA probes labelled with ${ }^{32} \mathrm{P}$ by random priming, specific for epidermal differentiation markers: keratin 14, keratin 10, involucrin and for the house-keeping gene 36B4 (in order to check equivalent loading). The cDNA for E7 was obtained by RT-PCR from total RNA, extracted from E6E7 cells.

corresponded with a decrease in the phosphorylation and in the DNA-binding activity of one of the ERK1/2 substrates, the transcriptional regulator c-Myc. Our data provide information relevant to the anti-proliferative effects of this CDK-inhibitor and its role as a potent anti-cancer agent on papilloma-transformed keratinocytes.

\section{Materials and methods}

Reagents. (R)-2-[[9-(1-methylethyl)-6-[(phenyl methyl) amino]-9H-purin-2-yl] amino]-1-butanol (CYC202) was from Cyclacel Ltd. For use in culture medium, CYC202 was dissolved at $100 \mathrm{mM}$ in DMSO and stored at $-20^{\circ} \mathrm{C}$.

The recombinant human epidermal growth factor (EGF) was purchased from R\&D Systems, dissolved according to the manufacturer's instructions (50 $\mu \mathrm{g} / \mathrm{ml}$ stock solution) and stored at $-20^{\circ} \mathrm{C}$.

Cell culture and treatment. The cell cultures were incubated at $37^{\circ} \mathrm{C}$ in a $5 \% \mathrm{CO}_{2}$ humidified atmosphere. The cell line E6 and E7, derived from normal human keratinocytes through stable transfection with HPV16 E6 and E7 genes was kindly provided by Dr Mark Pittelkow (Mayo Clinic, Rochester, USA). E6 and E7 cells and normal keratinocytes were grown in Epilife keratinocyte medium (Cascade Biologics), supplemented with growth factors, hormones and antibiotics. At $\sim 40 \%$ of the culture confluence, the cells were then grown under autocrine conditions by excluding all growth factors from the culture medium.

For treatment with CYC202, different amounts of the stock solution were added to the autocrine culture medium in order to obtain 0.1-30 $\mu \mathrm{M}$ CYC202. Control cultures were incubated with DMSO only.

Determination of cell viability by MTT assay. E6 and E7 cells were plated in $24-$ well plates at $5 \times 10^{3}$ cells $/ \mathrm{cm}^{2}$. After incubation for $24 \mathrm{~h}$ with different concentrations of CYC202 in a dose range between $0.1-30 \mu \mathrm{M}$, the medium was removed and substituted with $500 \mu \mathrm{l} /$ well of MTT solution $[0.5 \mathrm{mg} / \mathrm{ml}$ of 3-(4,5-dimethylthiazol-2-yl)-2,5-diphenyl tetrazolium bromide (Sigma)] and the cells were then incubated in for $2 \mathrm{~h}$ in the dark at $37^{\circ} \mathrm{C}$. MTT solution was then removed, and the cells were rinsed with phosphate-buffered saline (PBS). Formazan crystals in each dish were dissolved in $250 \mu \mathrm{l}$ of isopropanol during a 30-min incubation on a rocker platform. Depending on the intensity of the dye concentration, $100 \mu 1$ from each sample was diluted with isopropanol and distributed in a 96-well plate. The absorbance was spectrophotometrically measured at a wavelength of $570 \mathrm{~nm}$. The measurement was converted into a percentage of cell viability, using control cultures to determine $100 \%$ of cell viability. Each measurement was performed on quadruplicate culture wells and the experiment was repeated several times. The $\mathrm{CD}_{50}$ was determined with curve fitting by GraphPad software.

Determination of DNA synthesis. E6 and E7 cells were plated as above in 12-well plates and treated for $24 \mathrm{~h}$ with varying concentrations of CYC202. For the last $2 \mathrm{~h}$ of incubation, $1 \mu \mathrm{Ci}$ $\left[{ }^{3} \mathrm{H}\right]$-thymidine (ICN) was added to each well. The radioactive medium was then removed and the cells were washed three times with ice-cold PBS and precipitated in $10 \%$ trichloroacetic acid (TCA) for $10 \mathrm{~min}$ at $4^{\circ} \mathrm{C}$. The precipitates were dissolved in $1 \mathrm{ml}$ of $0.3 \mathrm{~N} \mathrm{NaOH}$ and $0.1 \%$ sodium dodecyl sulphate (SDS). The radioactivity in $500 \mu 1$ of each sample was counted in a Beckman liquid scintillation counter after the addition of Aqualuma. Triplicates of cultures for each concentration of CYC202 were analyzed and the experiment was performed several times. The cellular protein content was determined by the method of Lowry et al (15), and the rate of DNA synthesis was calculated per $\mu \mathrm{g}$ of protein content.

Detection of the clonogenic potential of E6 and E7 cell cultures. E6 and E7 cells were treated with 1-20 $\mu \mathrm{M}$ CYC202 for $24 \mathrm{~h}$ as above. After the treatment, the cells were trypsinized and then counted. A total number of 2000 cells were replated in $60-\mathrm{mm}$ Petri dishes and into fresh complete culture medium. These cultures were incubated for 7 days. At the end of the culture period, the cells were fixed with $4 \%$ formaldehyde solution in PBS, and then stained with $0.2 \%$ solution of crystal violet for $5 \mathrm{~min}$ at room temperature. The staining solution was discarded and the dishes were washed three times with distilled water before the photographing of the cell colonies.

Northern blot analysis. Poly(A) RNA was prepared from cultures of E6 and E7-transformed and normal keratinocytes using the method described by Schwab et al (16). The samples were resolved on $1.2 \%$ agarose-formaldehyde gel by electrophoresis for $3 \mathrm{~h}$ at $75 \mathrm{~V}$ and then transferred to ZetaProbe GT membrane (Bio-Rad). Hybridizations were performed overnight at $43^{\circ} \mathrm{C}$ with randomly primed and $[\alpha$ $\left.{ }^{32} \mathrm{P}\right]$ dCTP-labeled DNA probes for HPV16 E6 and E7 early genes, basal keratin 14, suprabasal keratin 10 and involucrin as previously described (17). In order to check equivalent loading and transfer of RNA, the blotted membranes were 


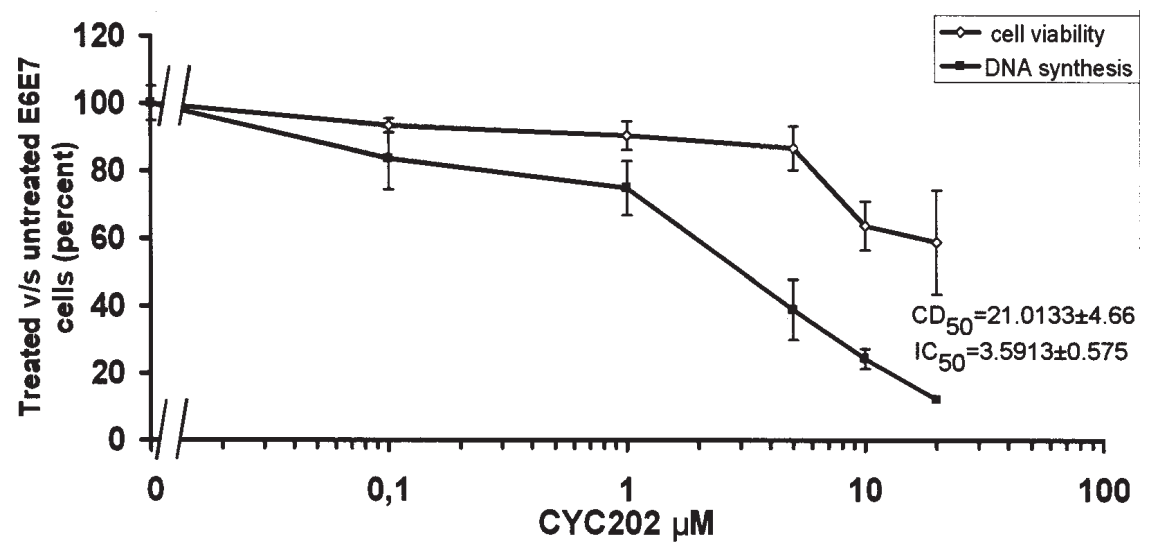

Figure 2. Comparison between cell viability and $\left[{ }^{3} \mathrm{H}\right]$-thymidine incorporation in cultures of E6E7 keratinocytes incubated with CYC202. E6E7 keratinocytes were treated for $24 \mathrm{~h}$ with different concentrations of CYC202 $(0.1-20 \mu \mathrm{M})$. The cellular viability and the measurement of [ $\left.{ }^{3} \mathrm{H}\right]$-thymidine incorporation into DNA was performed as it is described in Materials and methods. Data are presented in percent of untreated cells (100\%) \pm SD averaged from five different experiments. The concentrations which cause $50 \%$ reduction in cell viability $\left(\mathrm{CD}_{50}\right)$ and which inhibit cell proliferation by $50 \%$ (IC $\left.{ }_{50}\right)$ were calculated by curve fitting with GraphPad software.

further hybridized with a 36B4 cDNA probe $(18,19)$. The expression of poly(A) RNA was detected and measured with the Cyclone ${ }^{\mathrm{TM}}$ storage phosphor system (Packard BioScience Co.) after sufficient exposure time of the membrane.

Western blot analysis. After treatment with CYC202, the cells were lysed in a sample buffer $(0.125 \mathrm{M}$ Tris- $\mathrm{HCl}, \mathrm{pH} 6.8$, $20 \%$ glycerol, 4\% SDS, $0.2 \mathrm{M}$ dithiothreitol (DTT) in deionised water), detached by scraping and then cleared by centrifugation at $13,000 \mathrm{rpm}$ at $4^{\circ} \mathrm{C}$ for $15 \mathrm{~min}$. Protein concentration was quantified using Bio-Rad DC protein assay and equal amounts of protein were used for analysis on 10 or $12 \%$ SDS-PAGE. Resolved proteins were transferred overnight at $4{ }^{\circ} \mathrm{C}$ to Hybond-P: PVDF membrane (Amersham Biosciences). The membrane was then incubated with blocking buffer (5\% non-fat dry milk in $0.1 \%$ Tween-20/PBS). The immunodetection of phosphorylated HSP27, c-Myc and MAP kinases was performed respectively with rabbit antiphospho-HSP27 (Ser82) IgG (Upstate), rabbit anti-phospho c-Myc (Thr58/Ser62) IgG (Santa Cruz Biotechnology), mouse monoclonal IgG anti-phospho MAP kinase (ERK1/2), clone 12D4 (Upstate), mouse monoclonal $\mathrm{IgG}_{1}$ anti-phospho JNK (Santa Cruz Biotechnology) and rabbit polyclonal antiphospho p38[pTpY 180/182] (Cell Signalling Technology). After membrane-stripping, total HSP27, c-Myc, JNK, ERK1/2, p38 were detected respectively with the goat anti-HSP27 (Santa Cruz Biotechnology), mouse monoclonal $\mathrm{IgG}_{1} \mathrm{c}-\mathrm{Myc}$ (Santa Cruz Biotechnology), rabbit SAPK/JNK (Cell Signalling Technology), rabbit anti-MAP kinase (ERK1/2, Upstate) and the rabbit anti-p38 MAP kinase (Biosource). Primary antibodies were then revealed with anti-mouse, anti-goat and anti-rabbit horseradish peroxidase-conjugated antibodies (Dako Diagnostics). The detection was performed with Western blotting luminol reagent (Santa Cruz Biotechnology).

Electrophoretic mobility-shift assay (EMSA). Nuclear extracts were prepared from E6 and E7 cells treated with CYC202 $(0,5,10,20 \mu \mathrm{M})$. Cells were scraped and lysed in buffer A (10 mM HEPES pH 7.9, $1.5 \mathrm{mM} \mathrm{MgCl}_{2}, 10 \mathrm{mM} \mathrm{KCl}, 0.1 \mathrm{mM}$ EDTA, $0.1 \mathrm{mM}$ EGTA, $0.5 \mathrm{mM}$ DTT, $0.2 \mathrm{mM}$ phenyl- methylsulfonyl fluoride (PMSF), $1 \mu \mathrm{g} / \mathrm{ml}$ protease inhibitor mixture and $0.5 \%$ Nonidet P-40). Nuclei were pelleted by centrifugation at $13,000 \mathrm{rpm}$ for $10 \mathrm{~min}$ at $4^{\circ} \mathrm{C}$. Pellets were re-suspended in ice-cold hypotonic buffer C (10 mM HEPES $\mathrm{pH} 7.9,420 \mathrm{mM} \mathrm{NaCl}, 25 \%$ glycerol, $0.2 \mathrm{mM}$ EDTA, $0.2 \mathrm{mM}$ EGTA, $1.5 \mathrm{mM} \mathrm{MgCl}_{2}, 1 \mathrm{mM}$ DTT, $0.2 \mathrm{mM}$ PMSF and 1 $\mu \mathrm{g} / \mathrm{ml}$ protease inhibitor mixture), mixed vigorously by vortexing and centrifuged at $13,000 \mathrm{rpm}$ for $30 \mathrm{~min}$ at $4^{\circ} \mathrm{C}$. Protein concentration was determined by colorimetric assay (Bio-Rad).

A double-stranded end-labelled DNA oligonucleotide (5'-biotin-AGTTGACCACGTGGTCTGGG-3') with a consensus binding site of c-Myc/Max dimers (Alpha DNA) was incubated with the nuclear extracts. The binding reactions were carried out with $15 \mu \mathrm{g}$ of the respective nuclear extract protein, 0.5 pmol biotin-labelled DNA, $100 \mathrm{mM}$ $\mathrm{MgCl}_{2}, 1 \%$ Nonidet P-40, $50 \%$ glycerol, $1 \mu \mathrm{g} / \mu \mathrm{l}$ of poly(dA$\mathrm{dT})$ and $10 \mathrm{X}$ binding buffer $(100 \mathrm{mM}$ Tris $\mathrm{pH} 7.5,500 \mathrm{mM}$ $\mathrm{KCl}, 10 \mathrm{mM}$ dithiothreitol). The DNA-protein interaction was allowed to proceed for $15 \mathrm{~min}$ at room temperature. The protein-DNA complexes were resolved on $6 \%$ native polyacrilamide gel in $0.5 \mathrm{X}$ TBE and transferred to Biodyne ${ }^{\circledR} \mathrm{B}$ nylon membrane (Pierce). After transfer, the membrane was immediately cross-linked for $15 \mathrm{~min}$ on a UV transilluminator equipped with $312-\mathrm{nm}$ bulbs. A chemiluminescent detection was performed with Chemiluminiscent nucleic acid detection module (Pierce).

\section{Results}

Phenotype profile of E6 and E7-transformed keratinocytes. Firstly, we analysed the phenotype profile of the papillomatransformed keratinocytes (E6 and E7) compared to normal human keratinocytes (NHK), both grown in autocrine conditions. When epidermal keratinocytes gain confluence they are committed to differentiation (20). The cells begin to express the characteristic markers for this process such as keratin 1, keratin 10, and involucrin. E6 and E7 cells showed a delayed expression of the differentiation marker involucrin, which was concomitant with the expression of keratin 1 and 


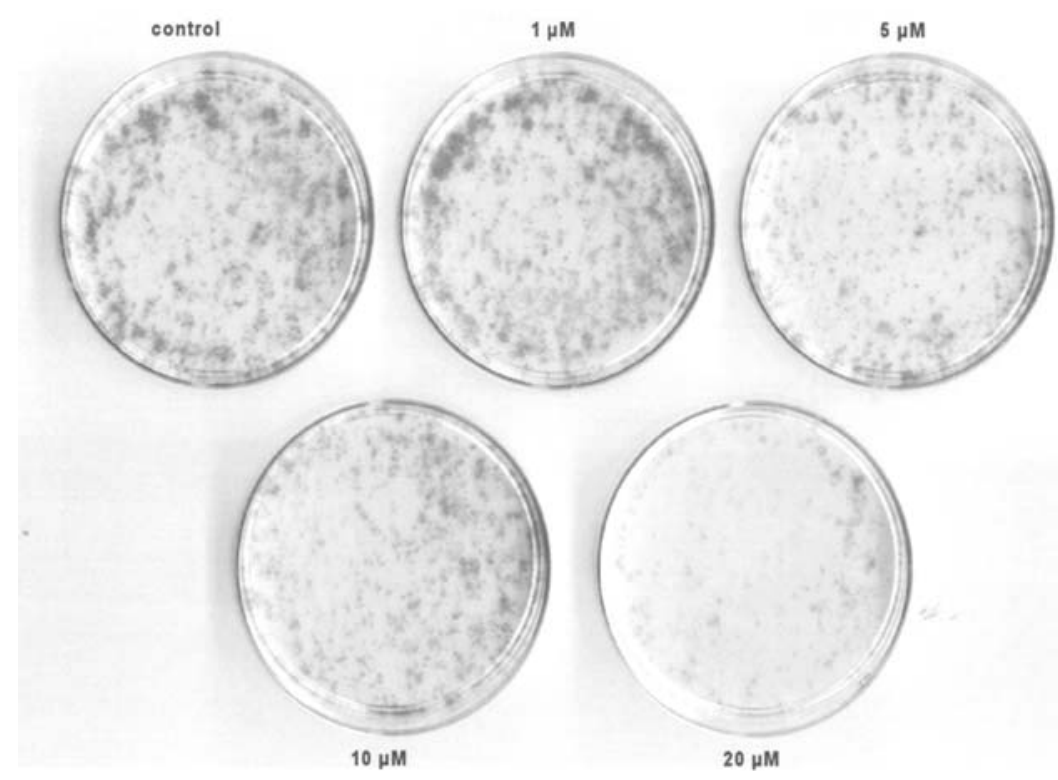

Figure 3. Clonal assay of E6E7 keratinocytes after CYC202 treatment. Subconfluent cultures of growing E6E7 keratinocytes were treated for 24 h with different concentrations of CYC202 (1-20 $\mu \mathrm{M})$, then the inhibitor was washed and the cultures trypsinized. The cells were counted and 2000 cells from each treatment were reseeded in 60-mm diameter Petri dishes using fresh complete culture medium containing all growth factors necessary for the cellular proliferation. After 7 days, the cell colonies were fixed and stained with crystal violet. The bottom of stained dishes was photographed in a scanner. Keratinocyte cultures treated with DMSO only were used as control.

keratin 10 (Fig. 1). The levels of the two keratins were elevated and compared to those in normal keratinocytes. To note, simultaneously with the expression of the differentiation markers, the level of the viral E7 was weakly decreased.

Dose-dependent growth inhibition by CYC202. We next examined the toxicity of the pharmacological agent CYC202 towards HPV16 E6- and E7-transformed keratinocytes. E6 and $\mathrm{E} 7$ cells, grown under autocrine conditions were exposed for $24 \mathrm{~h}$ to $\mathrm{CYC} 202$, ranging from $0.1-30 \mu \mathrm{M}$ (the viability at concentrations higher than $20 \mu \mathrm{M}$ is not shown) and cellular viability was determined by an MTT assay (Fig. 2). CYC202 induced a dose-dependent loss in cell viability. The $\mathrm{CD}_{50}$ value determined by curve fitting was $\sim 20 \mu \mathrm{M}$ $(21.0133 \pm 4.66 \mu \mathrm{M})$.

Next, we analysed whether CYC202 exerted an inhibitory effect on the cellular growth of these transformed cells. The synthesis of new DNA molecules was measured by the incorporation of radio-labelled thymidine $\left(\left[{ }^{3} \mathrm{H}\right]\right.$-thymidine) (Fig. 2). The level of the $\left[{ }^{3} \mathrm{H}\right]$-thymidine incorporation in the newly synthesised DNA was significantly inhibited by treatment for $24 \mathrm{~h}$ with $\mathrm{CYC} 202$ at all tested concentrations. The concentration at which the proliferation was inhibited at $\sim 50 \%$ $\left(\mathrm{IC}_{50}\right)$ was determined by curve fitting around $4 \mu \mathrm{M}$ CYC202 (3.5913 $\pm 0.575 \mu \mathrm{M})$.

The inhibition of cell growth by CYC202 was reversible. In order to evaluate whether the inhibition of the cellular growth by CYC202 on E6 and E7-transformed cells could be reversed after withdrawal of the drug, we performed a clonal test. E6 and E7 cells were treated for $24 \mathrm{~h}$ at specific concentrations $(1,5,10$ and $20 \mu \mathrm{M})$, and then the cells were trypsinized in order to plate them at a low density in a clonal assay (21). The concentrations for this experiment were chosen in the range of concentrations, shown to exert low toxicity and strong inhibition of the cellular growth (Fig. 2). Similarly to the previously obtained results with normal keratinocytes, the CDK inhibitor CYC202 didn't completely block the cellular growth and soon after withdrawal of the inhibitor, the viable cells started to divide and form colonies again. The lowest concentration of CYC202 $(1 \mu \mathrm{M})$ allowed similar clonogenicity of E6 and E7 cells to the one observed in control culture conditions (\% compared to the control). However, the number of colonies was decreased after an incubation with 5 and $10 \mu \mathrm{M} \mathrm{CYC} 202(\%)$ and only rare colonies were formed by the cells, plated after treatment with $20 \mu \mathrm{M} \mathrm{CYC202} \mathrm{(Fig.} \mathrm{3).}$

Growth arrest by CYC202 was associated with p38 MAPK activation, but not with ERK1/2 or JNK1/2 activation. To further investigate the effects of CYC202 on papillomatransformed E6 and E7 keratinocytes, we analyzed the phosphorylation (activation) of the kinases from three MAPK subfamilies (ERK1/2, p38 MAPK and JNK1/2), which are associated with the regulation of cellular proliferation, differentiation, senescence and apoptosis $(22,23)$.

The phosphorylation of ERK $1 / 2$ remained almost unchanged after treatment with CYC202 up to $10 \mu \mathrm{M}$ (Fig. 4). A small decrease was observed at a concentration of the inhibitor of $20 \mu \mathrm{M}$. Mitogenic stimulation with the epidermal growth factor (EGF) for $15 \mathrm{~min}$ increased the level of phoshorylated ERK1/2. However, EGF did not obviate the inhibitory effect of the highest concentration of CYC202 on the activation of ERK1/2, as at these conditions of treatment inhibition was observed again.

The level of active (phosphorylated) p38 MAPK was dosedependently elevated by CYC202 solely and in combination with EGF (Fig. 4). The most significant increase $\sim 7$-fold compared to control cultures, was observed at $20 \mu \mathrm{M}$ CYC202. The effect of the growth factor EGF on the 


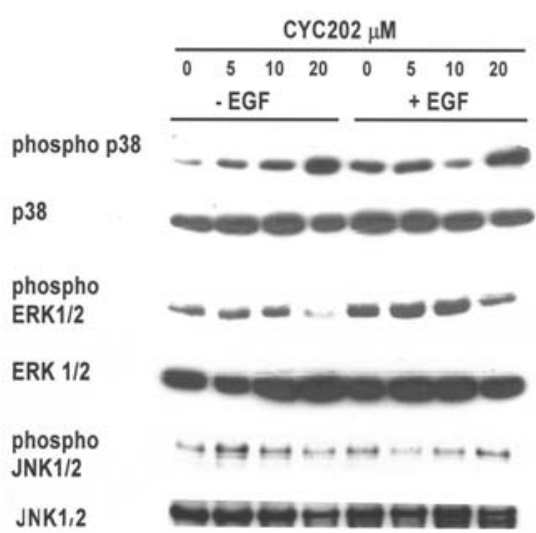

Figure 4. Analysis of the phosphorylation of ERK1/2, JNK1/2 and p38 MAPK kinase in E6E7 keratinocytes incubated with CYC202. E6E7 cells incubated with $0,5,10$ or $20 \mu \mathrm{M}$ CYC202 for $24 \mathrm{~h}$ and (or without) recombinant EGF $(10 \mathrm{ng} / \mathrm{ml})$ were lysed and equal amounts of proteins were used for Western blot analysis of the basal and phosphorylated ERK1/2, p38 MAPK and JNK1/2.

phosphorylation of p38 MAPK was comparable with that of the inhibitor. The combination of EGF with the highest dose of CYC202 results in analogical phosphorylation of p38 MAPK, similar to the level observed after treatment with this concentration of CYC202 alone.

The phosphorylation of the kinases from the third MAPK subfamily JNK1/2 was unchanged by CYC202 alone or in combination with EGF (Fig. 4). Short stimulation with EGF did not induce phosphorylation of JNK1/2 kinases in E6 and E7 keratinocytes.

After activation, each MAPK phosphorylates a spectrum of substrates, including different transcription factors $(22,23)$. Therefore we analyzed the activity of two MAPK effectors: the small heat shock protein 27 (HSP27), which is activated by p38 MAPK; and the transcription factor c-Myc, which is activated downstream of the ERK1/2 signaling pathway. As it was expected, the phosphorylation of c-Myc analogous to that of the ERK1/2 kinases was decreased by the highest concentration of CYC202 applied solely or when the treatment was succeeded by short stimulation with EGF (Fig. 5). However, the phosphorylation of HSP27 which is a substrate of p38 MAPK $(24,25)$ was strongly increased by 20 $\mu \mathrm{M}$ CYC202. Although, the activity of p38 kinase was elevated also by treatment with lower doses of the inhibitor, we did not observe any effect on the activation of HSP 27 by 5

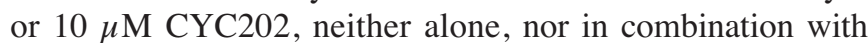
EGF. Stimulation with the growth factor alone had a minimal effect on the phosphorylation of HSP27, but when it was preceded by treatment with $20 \mu \mathrm{M} \mathrm{CYC} 202$ the increase was significant (Fig. 5).

Because binding to target sequences is essential for c-Myc function, we have further analyzed whether CYC202 interfered with the DNA binding of the Myc/Max complexes by EMSA. The binding of the protein to the target DNA sequence results in a single retarded band at electrophoresis. Inhibition with CYC202 up to $10 \mu \mathrm{M}$ had no effect on the c-Myc DNA-binding activity, however treatment with $20 \mu \mathrm{M}$ CYC202 decreased the binding of nuclear extracts to the synthetic oligonucleotide containing Myc/Max consensus sequence (Fig. 6).

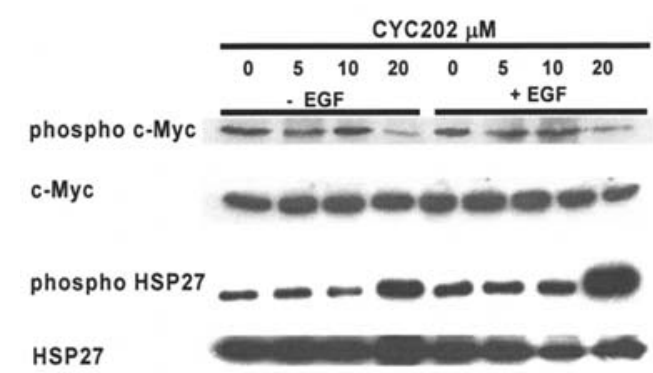

Figure 5. Analysis of the phosphorylation of c-Myc and HSP27 after incubation of E6E7 keratinocytes with CYC202. E6E7 keratinocytes were incubated for $24 \mathrm{~h}$ with CYC202 in concentrations of $0,5,10$, or $20 \mu \mathrm{M}$ and (or without) recombinant EGF $(10 \mathrm{ng} / \mathrm{ml})$. After lysis, Western blotting transferred equal amounts of proteins which were used for detection of phosphorylated and total c-Myc and HSP27 using specific antibodies.

\section{$\begin{array}{lllll}1 & 2 & 3 & 4 & 5\end{array}$}
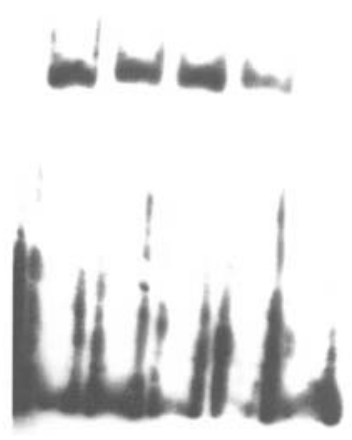

Figure 6. Electrophoretic mobility-shift assay. E6E7 keratinocytes were incubated for $24 \mathrm{~h}$ with CYC202 $(0,5,10$ or $20 \mu \mathrm{M})$. Nuclear extracts were prepared and EMSA analysis of Myc/Max binding activity was performed, as described in 'Materials and methods'. Lane 1: protein extract from control cultures, incubated with DMSO only; Lane 2: protein extract from cultures incubated with $5 \mu \mathrm{M}$ CYC202; Lane 3: protein extract from cultures incubated with $10 \mu \mathrm{M} \mathrm{CYC202;} \mathrm{Lane} \mathrm{4:} \mathrm{protein} \mathrm{extract} \mathrm{from}$ cultures incubated with $20 \mu \mathrm{M} \mathrm{CYC202;} \mathrm{Lane} \mathrm{5:} \mathrm{c-Myc} \mathrm{oligonucleotide}$ without protein extract.

\section{Discussion}

Many epithelial malignancies, including cervical cancer are often associated with small DNA viruses from the papilloma family. The replication of the viral genome is dependent on the host cell, and HPVs have developed several strategies to ensure cell cycle progression. Mainly two of the viral genes, E6 and E7, are implicated in cell transformation leading to continuous proliferation and immortalization of normal cells (10). The products of the E6 and E7 genes interact with tumour suppressors and this interaction abrogates the function of these regulatory molecules. One of the cell proteins, whose activities are interrupted by the expression of the viral oncogenes, is the cyclin-dependent kinase inhibitor p21 ${ }^{\text {Cip } 1}$. Jones et al show in their study that the abrogation of p21 Cip1 mediated inhibition of CDK2 activity is important for the uncoupling of the processes of keratinocyte proliferation and differentiation, leading to indefinite cellular proliferation (13). In this case, CYC202 might be a useful pharmacological 
inhibitor of the cell growth of papilloma-infected cells and perhaps could be applied for therapy of papilloma-induced malignancies. Therefore, in this study we investigated the action of the CDK-inhibitor CYC202 on HPV16 E6- and E7transformed keratinocytes.

To be useful for clinical application, similar to every anticancer agent, CYC202 must be several times more potent towards transformed cells, rather than inhibiting the growth of the normal human cells. In light of its nature, CYC202 is a more potent inhibitor of the cellular growth of highly proliferating cells (2). Despite the transformation, in our culture conditions, E6 and E7 cells proliferated almost in the same manner as autocrine cultures of normal keratinocytes. Even more, the E6 and E7 cells were still capable of differentiating. Accordingly, the gain in cell confluence was associated with the expression of keratinocyte differentiation markers keratin 1 , keratin 10 and involucrin, but compared to normal keratinocytes this expression was shortly delayed. This observation remains in accordance with the reports of other investigators suggesting that HPV16 E6- and E7-expressing keratinocytes have delayed differentiation, partially uncoupled from the cellular proliferation $(9,13)$. Nguyen et al have reported that although HPV16 E7 can delay differentiationinduced growth arrest, HPV16 E7-expressing cells are still capable of differentiating and the viral gene does not interfere with differentiation-specific gene expression (11).

The first step for the analysis of the effects of CYC202 on culture of E6 and E7-transformed keratinocytes was to determine the effective dose of the agent at inhibiting cell growth without affecting the cell viability. Significant growth inhibition was observed at weakly toxic concentrations. The distinction between the concentration of CYC202 with a strong cytotoxic effect, e.g. $\mathrm{CD}_{50}$, and the concentration that effectively inhibits the cell proliferation, e.g. $\mathrm{IC}_{50}$, permits the utilization of CYC202 for E6 and E7 growth inhibition. The effective concentration of CYC202 for growth inhibition of E6 and E7-transformed keratinocytes was almost 2-fold lower than that exerted towards proliferating normal keratinocytes (6). Probably, the analogical proliferative state of E6 and E7- transformed and normal keratinocytes is the reason for almost the same susceptibility to growth inhibition by CYC202.

In addition, with the inhibition of the cell cycle on the level of CDK kinases, CYC202 interferes with several signal transduction pathways and this has consequences for the cell's choice between proliferation, differentiation or death $(3,26,27)$. The MAPK signaling pathways are implicated in the regulation of these processes and have been shown to respond to a broad range of external stresses and drugs, including CYC202 $(3,22)$. In general, the ERK cascade is believed to mediate both cell proliferation and survival, whereas p38 MAPK and JNK are activated in response to cellular stress $(28,29)$.

Complementary to the inhibition of DNA synthesis, CYC202 abolished the proliferative effects of the transforming viral genes also at the level of the signal-transduction pathways. In accordance, the activities of the MAP kinases associated with the cellular growth, ERK1/2, were inhibited. The transcriptional regulator c-Myc is necessary for keratinocyte proliferation and is one of the downstream effectors of the ERK1/2 signaling pathway (23). In addition, it was reported that E6 of HPV16 associates with Myc and this complex functions to transactivate the gene of human telomerase reverse transcriptase and hence constitutes a major immortalizing activity of E6 (30). Therefore, the phosphorylation of c-Myc on Thr58/Ser-62, targeted by active ERK1/2 MAP kinases, was inhibited by treatment with $20 \mu \mathrm{M}$ CYC202, in correlation with the inhibition of the cellular growth and the phosphorylation of ERK1/2 kinases. Even more, the highest concentration of CYC202 decreased c-Myc DNA-binding activity, which is essential for its function as a transcriptional regulator, and this result confirmed the negative effect of CYC202 on the activity of some signaling molecules implicated in the regulation of the cellular proliferation.

Recent studies reported the reverse correlation between the activity of the other subfamily of MAP kinases, p38 MAPK, and that of ERK1/2, as a result of complex formation between these kinases $(31,32)$. This reciprocal activity of the two subfamilies of MAP kinases, was observed previously when we studied the effects of CYC202 on normal human keratinocytes (6). Analogically, in E6 and E7 cells the inhibition of ERK1/2 by the highest concentration used (20 $\mu \mathrm{M})$ coincided with a strong increase in the phosphorylation of the stress kinase p38 MAPK. The activity of this kinase was proved further by the phosphorylation of one of its substrates, the small heat shock protein hsp27 $(24,25)$. In a previous study, we attributed the induction of p38 MAPK and the subsequent phosphorylation of hsp27 to a stress response towards the inhibitor CYC202 (6). However, here we showed that the activity of the other subfamily MAP kinases associated with stress reactions, JNK1/2, was not affected by treatment with CYC202. In light of the evidence, that MAPK can influence cell cycle progression and the p38 MAPK pathway is a primary pathway activated by agents that inhibit the progression of the cell cycle $(29,33)$, the activation of this kinase by CYC202 possibly is a result of cell cycle arrest induced by the CDK-inhibitor.

In conclusion, this study demonstrated that HPV16 E6 and E7-transformed keratinocytes are sensitive to the antiproliferative actions of the CDK-inhibitor CYC202. The inhibition of the cellular growth was associated with changes in the activity of some molecules, participating in the regulation of this process. CYC202 inhibits the activity of ERK1/2 MAP kinases, but strongly activates the stress kinase p38 MAPK. These data suggest an important interplay between p38 MAPK and cell cycle control and also provide additional insights for the potency of the CDK-inhibitor CYC202.

\section{Acknowledegments}

This study was supported by a grant No. 21/2007 from the Medical University of Sofia. HPV16 E6 and E7 keratinocytes were kindly provided by Professor M. Pittelkow (Mayo Clinic, USA).

\section{References}

1. Meijer L, Borgne A, Mulner O, et al: Biochemical and cellular effects of roscovitine, a potent and selective inhibitor of the cyclin-dependent kinases cdc2, cdk2 and cdk5. Eur J Biochem 243: 527-536, 1997.

2. McClue SJ, Blake D, Clarke R, et al: In vitro and in vivo antitumour properties of the cyclin-dependent kinase inhibitor CYC202 (R-roscovitine). Int J Cancer 102: 463-468, 2002. 
3. Whitteker SR, Walton MI, Garrett MD and Workman P: The Cyclin-dependent kinase inhibitor CYC202 (R-roscovitine) inhibits retinoblastoma protein phosphorylation, causes loss of Cyclin D1, and activates the mitogen-activated protein kinase pathway. Cancer Res 64: 262-272, 2004.

4. Mgbonyebi OP, Russo J and Russo IH: Roscovitine induces cell death and morphological changes indicative of apoptosis in MDAMB-231 breast cancer cells. Cancer Res 15: 1903-1910, 1999.

5. Alessi F, Quarta S, Savio M, et al: The cyclin-dependent kinase inhibitors olomoucine and roscovitine arrest human fibroblasts in G1 phase by specific inhibition of CDK2 kinase activity. Exp Cell Res 245: 8-18, 1998.

6. Atanasova G, Jans R, Zhelev N, Mitev V and Poumay Y: Effects of the cyclin-dependent kinase inhibitor CYC202 ( $R$-roscovitine) on the physiology of cultured human keratinocytes. Biochem Pharmacol 70: 824-836, 2005.

7. Fischer PM and Gianella-Borradori A: CDK inhibitors in clinical development for the treatment of cancer. Expert Opin Investig Drugs 12: 955-970, 2003.

8. Meijer L and Raymond E: Roscovitine and other purines as kinase inhibitors. From starfish oocytes to clinical trials. Acc Chem Res 36: 417-425, 2003.

9. Nees M, Geoghegan J, Munson P, Prabhu V, Liu Y, Androphy E and Woodworth C: Human papillomaavirus type 16 E6 and E7 proteins inhibit differentiation-dependent expression of transforming growth factor- $\$ 2$ in cervical keratinocytes. Cancer Res 60: 4289-4298, 2000.

10. Hawley-Nelson P, Vousden KH, Hubert NL, Lowy DR and Schiller JT: HPV16 E6 and E7 proteins cooperate to immortalize human foreskin keratinocytes. EMBO J 8: 3905-3910, 1989.

11. Nguyen DX, Westbrook TF and McCance DJ: Human papillomavirus type $16 \mathrm{E} 7$ maintains elevated levels of the cdc25A tyrosine phosphatase during deregulation of cell cycle arrest. J Virol 76: 619-632, 2002.

12. Martin LG, Demers W and Galloway DA: Disruption of the G1/S transition in human papillomavirus type 16 E7-expressing human cells is associated with altered regulation of cyclin E. J Virol 72: 975-985, 1998 .

13. Jones DL, Alani RM and Münger K: The human papillomavirus E7 oncoprotein can uncouple cellular differentiation and proliferation in human keratinocytes by abrogating p21 Cip1mediated inhibition of cdk2. Genes 11: 2101-2111, 1997.

14. Westbrook TF, Nguyen DX, Thrash BR and McCance DJ: E7 abolishes Raf-induced arrest via mislocalization of $\mathrm{p} 21^{\mathrm{Cip} 1}$. Mol Cell Biol 22: 7041-7052, 2002.

15. Lowry OJ, Rosebrough NJ, Farr AL and Randall RJ: Protein measurements with Folin phenol reagent. J Biol Chem 193: 265-275, 1951

16. Schwab M, Alitalo K, Varmus HE, Bishop JM and George D: A cellular oncogene (c-Ki-ras) is amplified, over expressed and located with karyotypic abnormalities in mouse adrenocortical tumour cells. Nature 303: 497-501, 1983.

17. De Potter IY, Poumay Y, Squillace KA and Pittelkow MR: Human EGF receptor (HER) family and heregulin members are differentially expressed in epidermal keratinocytes and modulate differentiation. Exp Cell Res 271: 315-328, 2001.
18. Laborda J: 36B4 cDNA used as an estradiol-independent mRNA control is the cDNA for human acidic ribosomal phosphoprotein PO. Nucleic Acids Res 19: 3998, 1991.

19. Stoll SW, Kansra S, Peshick S, et al: Differential utilization and localization of ErbB receptor tyrosine kinases in skin compared to normal and malignant keratinocytes. Neoplasia 3: 339-350, 2001.

20. Poumay Y and Pittelkow MR: Cell density and culture factors regulate keratinocyte commitment to differentiation and expression of suprabasal K1/K10 keratins. J Invest Dermatol 104: 271-276, 1995

21. Wille JJ Jr, Pittelkow MR, Shirpley GD and Scott RE: Integrated control of growth and differentiation of normal human keratinocytes cultured in serum free medium: clonal analyses, growth kinetics and cell cycle studies. J Cell Physiol 121: 31-44, 1984

22. Eckert RL, Efimova T, Dashti SR, et al: Keratinocyte survival, differentiation, and death: many roads lead to mitogen-activated protein kinase. J Investig Dermatol Symp Proc 7: 36-40, 2002

23. MacCorkle R and Tan T: Mitogen-activated protein kinases in cell-cycle control. Cell Biochem Biophys 43: 451-461, 2005.

24. Garmyn M, Mammone T, Pupe A, Gan D, Declercq L and Maes D: Human keratinocytes respond to osmotic stress by p38 Map kinase regulated induction of HSP70 and HSP27. J Invest Dermatol 117: 1290-1295, 2001

25. Niwa M, Hotta K, Kanamori Y, et al: Involvement of p38 mitogen-activated protein kinase in heat shock protein 27 induction in human neutrophils. Eur J Pharmacol 466: 245-253, 2003.

26. Wesierska-Gadek J, Gueorguieva M and Horky M: Dual action of cyclin-dependent kinase inhibitors: induction of cell cycle arrest and apoptosis. A comparison of the effects exerted by roscovitine and cisplatin. Pol J Pharmacol 55: 895-902, 2003.

27. Bach S, Knockaert M, Reinhardt J, et al: Roscovitine targets, protein kinases and pyridoxal kinase. J Biol Chem 280 31208-31219, 2005

28. Kyriakis JM and Avruch J: Mammalian mitogen-activated protein kinase signal transduction pathways activated by stress and inflammation. Physiol Rev 81: 807-869, 2001

29. Zarubin $T$ and Han J: Activation and signalling of the $\mathrm{p} 38$ MAP kinase pathway. Cell Res 15: 11-18, 2005.

30. Veldmann T, Liu X, Yuan H and Schleger R: Human papillomavirus E6 and Myc proteins associate in vivo and bind to and cooperatively activate the telomerase reverse transcriptase promoter. Proc Natl Acad Sci USA 100: 8211-8216, 2003.

31. Efimova T, Broome AM and Eckert RL: A regulating role for p38 delta MAPK in keratinocyte differentiation. Evidence for p38 delta-ERK $1 / 2$ complex formation. J Biol Chem 278: 34277-34285, 2003 .

32. Zhang H, Shi X, Hampong M, Blanis L and Pelech S: Stressinduced inhibition of ERK 1 and ERK2 by direct interaction with p38 MAP kinase. J Biol Chem 276: 6905-6908, 2001

33. Deacon K, Mistry P, Chernoff J, Blank JL and Patel R: p38 mitogen-activated protein kinase mediates cell death and p21activated kinase mediates cell survival during chemotherapeutic drug-induced mitotic arrest. Mol Biol Cell 14: 2071-2087, 2003. 